\title{
Clay minerals damage quantification in sandstone rocks using core flooding and NMR
}

\author{
Muhammad Shahzad Kamal ${ }^{1} \cdot$ Mohamed Mahmoud $^{2} \cdot$ Mohammed Hanfi $^{2} \cdot$ Salaheldin Elkatatny ${ }^{2} \cdot$ \\ Ibnelwaleed Hussein ${ }^{3}$
}

Received: 9 March 2018 / Accepted: 10 June 2018 / Published online: 14 June 2018

(c) The Author(s) 2018

\begin{abstract}
Sandstone oil reservoirs consist of different clay minerals such as kaolinite, illite, and chlorite. These clay minerals highly affect the formation damage during enhanced oil recovery (EOR) and well stimulation operations in these reservoirs. No attention was paid to investigate the effect of these clay minerals on the formation damage during different reservoir processes. In addition, no solution was introduced to mitigate the effect of clay minerals on the formation damage in sandstone reservoirs. In this study, the effect of clay mineral contents and type on the formation damage was studied in detail by injecting water and $\mathrm{HCl}$ as damaging fluids. Bandera grey, Berea, and Bandera brown sandstone rocks with various clay mineral contents were studied. XRD was used to characterize the sandstone rocks to determine the clay type and content in each rock. Two core plugs from each rock were selected for $\mathrm{HCl}$ and water injection. Core flooding experiments were performed to measure the initial and final permeability. In the core flooding experiments, fluids were injected into the cores at $25{ }^{\circ} \mathrm{C}$ and at a backpressure of $1000 \mathrm{psi}$. SEM was carried out before and after flooding for the tested rocks to locate the change in the clay distribution inside the rocks. The NMR analysis of core samples was done before and after flooding with the damaging fluid to quantify the formation damage and to find the possible damaging mechanism. NMR was used to locate the damage inside the rock due to the migration of clay minerals. Based on the core flooding, SEM, and NMR analysis, the maximum damage by the fresh water took place in Berea sandstone core due to fine migration and clay swelling. The illite clay mineral and chlorite can cause the formation damage on $\mathrm{HCl}$ injection. Illite can break down and migrates in the cores during the acid injection. In sandstone acidizing, chlorite clay mineral caused iron hydroxide precipitation inside the cores during treatment with mud acid. NMR showed that clay minerals plugged the pore throats of the rocks and reduced the rock permeability during the injection of fresh water.
\end{abstract}

Keywords Clay minerals $\cdot$ Acidizing $\cdot$ Sandstone $\cdot$ Enhanced oil recovery $\cdot$ Core flooding

\section{Introduction}

Mohamed Mahmoud

mmahmoud@kfupm.edu.sa

1 Center of Integrative Petroleum Research, College of Petroleum Engineering and Geosciences, King Fahd University of Petroleum and Minerals, Dhahran 31261, Saudi Arabia

2 Petroleum Engineering Department, College of Petroleum Engineering and Geosciences, King Fahd University of Petroleum and Minerals, Dhahran 31261, Saudi Arabia

3 Gas Processing Center, College of Engineering, Qatar University, PO Box 2713, Doha, Qatar
Formation damage is attributed to many processes such as drilling, completion, acidizing, and enhanced oil recovery (EOR). The damage caused by drilling solids depends mainly on the distribution of the pore size, wellbore overpressure, and particle size distribution in the drilling fluids. The laboratory experimental results suggest that damage from drilling particles to the well productivity can be as high as $10 \%$ depending on the invasion depth. However, practically in the field, the situation may differ from the lab tests in terms of penetration of mud particles which may be due to very porous zones or "micro-fracturing" during drilling pressure surges. Cement filtrate can also damage the permeability of the formation in different ways (Krueger 1988). 
Formation damage could also result due to plugging of the formation. Asphalts, the formation of fines, inorganic scales, and waxes are the main source of plugging. The plugging problem has a major effect on rapid declining of natural depletion of a field. During the production operation, the precipitation of organic and inorganic materials may also result in a reduction in the production or plugging the well. Inorganic scales such as $\mathrm{CaCO}_{3}$ and $\mathrm{CaSO}_{4}$ are of the most common well-plugging conditions which occurs within the tubing string. Organic scale materials such as paraffin could also precipitate near the well or inside the wellbore. Adsorption and retention of viscoelastic surfactant (VES) were observed by several studies (Curbelo et al. 2007; Paria and Khilar 2004; Patzkó and Dékány 1993; ShamsiJazeyi et al. 2014). Viscoelastic surfactants are used in stimulation and EOR and could cause the formation damage. The adsorption and retention of VES and other surfactants from aqueous solution on the reservoir rock could result in reducing the permeability of the rock (Yu et al. 2011). Different polymer additives used in drilling, completion and EOR could also reduce the permeability due to plugging in pore throats of the rock (Audibert et al. 1999).

The formation damage could also result due to interactions of different minerals present in the sandstone rocks with the different injected fluids. These minerals can be sand, clays, oxides, carbonates, and zeolite (Mahmoud et al. 2015). Kaolinite, smectite, illite, and chlorite are four main clay minerals present in the sandstone formation (Wilson et al. 2014). Clay can be either structural clay or dispersed clay. Dispersed clays are silicate clay minerals that attached to the rock mineral surfaces. Nesham defined the three different types of dispersed clay based on the clay crystal structure and location on pore walls or within inter-granular pores and pore throats and divided it into three groups (a) discrete particle, (b) pore lining, and (c) pore bridging (Neasham 1977). Discrete particle clays developed as pseudo-hexagonal crystals such as plates, attached to pore walls or occupying inter-granular pores. Pore-lining clays are those attached to pore walls, which appear as long and thin clay coating. Illite, chlorite, and montmorillonite were observed with pore-lining crystal morphologies. Pore-bridging clays are also attached to the pore walls. This type of clays includes illite, chlorite, and montmorillonite. Clay morphology of the high permeability sands shows that the discrete particle type is the dominant type affecting the permeability in high permeability cores. Whereas the intermediate permeability sands are affected mostly by the pore-lining variety. On the other hand, the low permeability sand contains pore-bridging types of clays.

The interactions of clays and other minerals with water and $\mathrm{HCl}$ could result in dissolution, precipitation, plugging, clay swelling, and fine migration that may cause formation damage (Al-Yaseri et al. 2015; Clarke 2014; Hayatdavoudi and Ghalambor 1996; Simon and Anderson 1990; Zhou et al. 1995). Interaction of water with different clays could result in clay swelling and fine migration. This can reduce permeability due to plugging and porosity by surface deposits. Hydrochloric acid can react with different minerals and dissolve them. The reactions of acid with certain clay at specific conditions can also cause precipitation. Priisholm et al. conducted core flooding experiments on samples from the Gassum and Haldager formations to determine the reservoir damage by clay swelling and/or fine migration (Priisholm et al. 1987). Based on the core analysis results, both porosity and permeability change with small changes caused by lithofacies variations. An air permeability increased about $3 \%$ when the plugs cleaned with methanol to remove precipitated salts from pores. The results obtained from the SEM and X-ray diffraction technique showed that the tested samples contain $3-12 \%$ clay minerals. Clays found to be critical to both particle migration and rock/fluid interactions. The kaolinite was the only clay mineral present in the Haldager formation, whereas the Gassum formation contains authigenic kaolinite, chlorite, illite, and mixed layer clays. Porosity and permeability may change significantly within small distances in the reservoir. The adsorbed water in clay mineral decreases the density of the grain. The flow experiments indicated that both Haldager and the Gassum formations are sensitive to change in differential pressure, flow direction, and brine composition. Both formations produced fines that are mainly produced when pumping is stopped and restarted and at major changes in flow rates. The diagram of fine production related to porosity shows inverse relationship. The permeability decreased when the plugs flushed with deionized water and the permeability could not be restored by flow reversals in the plugs with swelling clays.

The clays can have a huge impact on the formation damage due to interactions with different types of fluids. Therefore, it is of utmost importance to investigate the impact of different clay minerals on formation damage and governing mechanism. In most of the previous literature, the clay damage in sandstone reservoirs was characterized in the laboratory using permeability and pressure drop profile measurements and no quantitative measures were provided to describe the damage location (Ghofrani et al. 1992; Hayatdavoudi and Ghalambor 1996; Priisholm et al. 1987). No attention was made to identify the damage location in the rock due to interactions of minerals with injection fluids. Little efforts were made to identify the damaging mechanism (clay swelling, clay migration, dissolution, and precipitation) in the presence of different rock minerals.

The objectives of this study are to evaluate the damage caused by different clay minerals in sandstone rocks during stimulation and enhanced oil recovery processes using core flooding, NMR, and SEM analysis. The damage due to $\mathrm{HCl}$ acid injection in sandstone rocks was evaluated previously 
by permeability reduction with no further investigation to the location of the damage and the change in the pore-size distribution inside the rock. In this study, the change in pore size distribution, as well as the reduction in the pore size, was quantified using NMR.

\section{Materials and equipment}

The experiments were conducted using Bandera brown sandstone, Berea sandstone, and Bandera grey sandstone. The core plugs of dimensions 1.5-inch diameter and 3-inch length were used. For Berea sandstone and Bandera grey sandstone, $3 \mathrm{wt} \% \mathrm{KCl}$ was used as a compatible fluid to measure the permeability. However, $5 \mathrm{wt} \% \mathrm{KCl}$ was used for Bandera brown sandstone. While $15 \mathrm{wt} \% \mathrm{HCl}$ and fresh water were used as a damaging fluid since they affect the clay minerals in the sandstone. All solutions were prepared in deionized water. The mineralogical compositions of the different sandstone cores are listed in Table 1.

Core flooding setup was used to measure the initial and final permeability of core samples. The core plugs were dried in an oven at $60{ }^{\circ} \mathrm{C}$. The dried core plugs were vacuumed and saturated with $\mathrm{KCl}$ solution under a pressure of $1000 \mathrm{psi}$ at room temperature for $24 \mathrm{~h}$. The pore volume was calculated by saturation weight method. The core was flooded by $\mathrm{KCl}$ at four different rates to measure the initial permeability. The permeability was measured using the Darcy law. The pressure drop readings were recorded when the flow stabilized. A back-pressure regulator adjusted gradually up to $1000 \mathrm{psi}$ and a confining pressure of $1700 \mathrm{psi}$ was set. The formation damage was evaluated by comparing the initial and final permeabilities of each core sample. After measuring the initial permeability, the core plug was flooded with damaging fluid (fresh water or $\mathrm{HCl}$ ) at a constant injection rate of $5 \mathrm{~cm}^{3} / \mathrm{min}$ (from the wellbore to the formation direction). The cores were back flooded (from the formation to the wellbore direction) to measure the final permeability with the same fluids used for initial permeability

Table 1 Mineralogy of sandstone cores used in this study (wt\%)

\begin{tabular}{llll}
\hline Mineral & Berea & Bandera Brown & Bandera Grey \\
\hline Quartz & 87 & 68.6 & 57 \\
Dolomite & 1.0 & - & 16 \\
Calcite & 2.0 & - & - \\
Feldspar & 3.0 & 6.1 & - \\
Kaolinite & 5.0 & 0.7 & 3.0 \\
Illite & 1.0 & 5.2 & 10 \\
Chlorite & 2.0 & 7.4 & 1.0 \\
Plagioclase & - & 12 & 12 \\
\hline
\end{tabular}

measurement. The change in the permeability and pressure drop can be used to assess the formation damage.

The formation damage was also assessed using the NMR equipment. A bench-top rock core analyzer NMR from Oxford Instruments (GeoSpec2) were used for NMR-T2 relaxation experiments. The NMR can handle core size of maximum 3.5 in length and 2 in diameter. The data acquisition was completed using advanced software from Green Imaging Technologies. All NMR experiments were performed with a resonating frequency of $2.2 \mathrm{MHz}$ at an ambient temperature. 16 replicate scans were averaged to get a single exponential decay curve. The cores were analyzed by NMR before flooding to measure the porosity and depict the baseline T2 signal distribution. After flooding with damaging fluid ( $\mathrm{HCl}$ or fresh water), the cores were analyzed again by NMR to measure the alteration of the $\mathrm{T} 2$ signal distribution and porosity.

Scanning electron microscope (SEM) was also used to take high-resolution images of the core samples and to assess the formation damage by damaging fluid. The SEM used in this work was JSM-6610LV from JEOL. The highresolution image was captured using a high energy beam of electrons.

\section{Results and discussion}

Formation damage was assessed using core flooding experiments (permeability comparison and pressure drop profile), NMR T2 response before and after flooding, and comparison of rock morphology before and after flooding using SEM.

A total of six core flooding experiments were performed using water and $15 \mathrm{wt} \% \mathrm{HCl}$ as damaging fluids. Core selection was made based on different mineralogy and clay contents. Three different classes of sandstone cores used were Bandera grey, Bandera brown, and Berea sandstone. From each class, two core plugs were used to assess formation damage by water and $15 \mathrm{wt} \% \mathrm{HCl}$.

Figure 1 shows the pressure drop profile across the Bandera Grey sandstone (BR1) core when water was injected as the damaging fluid into the core. The final to initial permeability ratio of the BR 1 core was 0.34 as the initial permeability of the core was reduced from 48.5 to $16.6 \mathrm{md}$ after injection of water. The pressure drop was also increased from 10 to 70 psi for sample BR1. Both permeability reduction and increase in the pressure drop indicates the formation damage. The increase in the pressure drop and permeability reduction of BR1 due to injection of fresh water can be attributed to the solid migration that resulted from the salinity contrast between the $3 \mathrm{wt} \% \mathrm{KCl}$ solution and fresh water. The mineral composition analysis reveals that Bandera Grey sandstone core contains $3 \mathrm{wt} \%$ kaolinite and $10 \mathrm{wt} \%$ illite. On interactions with water, illite can swell and migrate to the

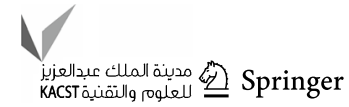




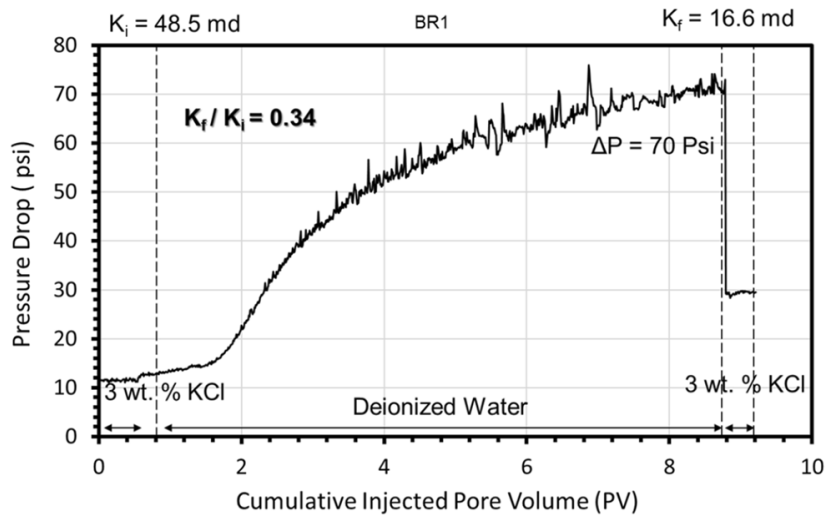

Fig. 1 Pressure drop across the sample Bandera Grey sandstone (BR1) as the deionized water injected at $5 \mathrm{~cm}^{3} / \mathrm{min}$ (backpressure $=1000 \mathrm{psi}$, confining pressure $=1700 \mathrm{psi}$ )

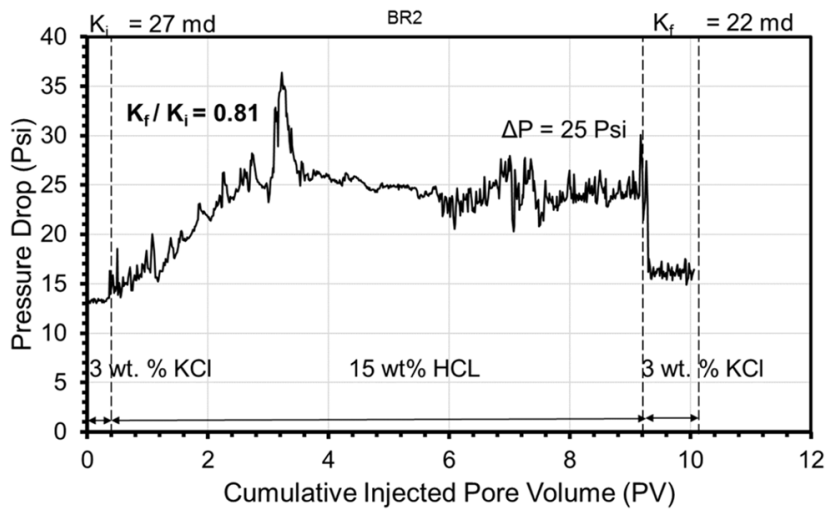

Fig. 2 Pressure drop across the sample Bandera Grey sandstone (BR2) as the $15 \mathrm{wt} \% \mathrm{HCl}$ injected at $5 \mathrm{~cm}^{3} / \mathrm{min}$ (backpressure $=1000 \mathrm{psi}$, confining pressure $=1700 \mathrm{psi}$ )

pore throat. The kaolinite is also responsible for the migration since it attached to the surface of the pores. The damage mechanism can be attributed to swelling-induced fine migration. Figure 2 depicts the pressure drop across Bandera Grey sandstone (BR2) when $15 \mathrm{wt} \% \mathrm{HCl}$ was used as damaging fluid. The increase in pressure drop was less compared to the increase in the pressure drop when water was used as damaging material in core BR1. The final to initial permeability ratio was 0.81 which is much higher compared to core BR1. The pressure drop profile and permeability data suggest that $\mathrm{HCl}$ was less damaging compared to fresh water for Bandera Grey sandstone. There are competing mechanisms due to the reaction of $\mathrm{HCl}$ with different rock minerals. $\mathrm{HCl}$ reacted mainly with chlorite, dolomite, and illite which caused the formation of a reaction product. $\mathrm{HCl}$ can break the illite and reaction products can result in fine migration. The reaction of $\mathrm{HCl}$ with chlorite could result in the formation of iron hydroxide precipitates with high viscosity. The dissolution of dolomite is also occurring at the same time because the

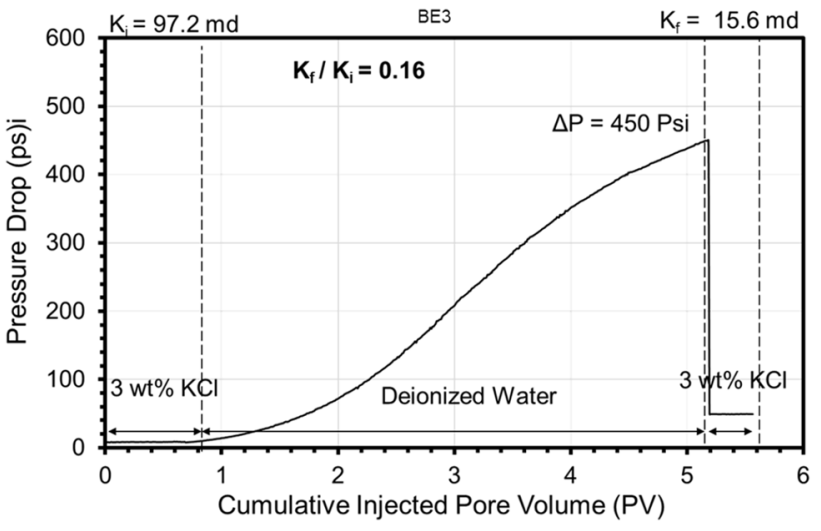

Fig. 3 Pressure drop across the sample Berea sandstone (BE3) as the deionized water injected at $5 \mathrm{~cm}^{3} / \mathrm{min}$ (backpressure $=1000 \mathrm{psi}$, confining pressure $=1700 \mathrm{psi}$ )

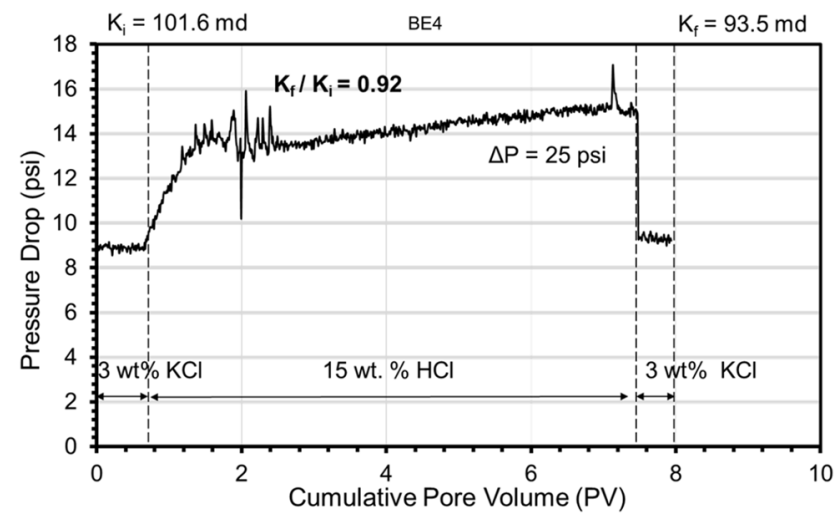

Fig. 4 Pressure drop across the sample Berea sandstone (BE4) as the $15 \mathrm{wt} \% \mathrm{HCl}$ injected at $5 \mathrm{~cm}^{3} / \mathrm{min}$ (backpressure $=1000 \mathrm{psi}$, confining pressure $=1700 \mathrm{psi}$ )

core contains almost $16 \mathrm{wt} \%$ dolomite. In summary, based on the core flooding data, fresh water was found to be more damaging to Bandera Grey sandstone core compared to 15 wt $\% \mathrm{HCl}$. The dolomite dissolution should enhance the permeability, while as the chlorite and illite interactions with the acid cause damage. In this case, the damage dominates the permeability enhancement by dolomite dissolution.

The mineral composition analysis of Berea sandstone indicates that it has higher kaolinite contents compared to the Bandera Grey sandstone rock. Similar experiments were repeated using Berea sandstone core to assess the impact on formation damage by injecting fresh water and $15 \mathrm{wt} \% \mathrm{HCl}$. Figures 3 and 4 show the pressure drop profile across the Berea sandstone cores by injecting fresh water and $15 \mathrm{wt} \%$ $\mathrm{HCl}$, respectively. For fresh water, the pressure drop across the core (BE3) increased up to $450 \mathrm{psi}$. A significant reduction in the permeability of the core was also noted. The permeability decreased from 97.2 to $15.6 \mathrm{md}$ and final to initial permeability ratio was 0.16 . This indicates the significant 
formation damage by injecting the fresh water. The damage in the Berea sandstone (BE3) core was significantly higher compared to the formation damage in Bandera Grey sandstone (BR1). The higher formation damage is due to a higher percentage of kaolinite (5 wt\%) in Berea sandstone which promotes the fine migration when water was flooded. Like Bandera Grey core, $\mathrm{HCl}$ was less damaging to Berea compared to fresh water (Fig. 4). Permeability reduction and change in pressure drop across the Berea (BE4) was not significant. The pressure drop increases from 9 to $25 \mathrm{psi}$ and the permeability decrease from $101.6 \mathrm{md}$ to $93.5\left(K_{\mathrm{f}} / K_{\mathrm{i}}=0.92\right)$. In summary, the water was more damaging to Berea compared to Bandera Grey owing to higher kaolinite contents in Berea. However, $15 \mathrm{wt} \% \mathrm{HCl}$ has an almost similar level of damage to Bandera Grey and Berea.

The fresh water and $\mathrm{HCl}$ were also injected in two core plugs of Bandera brown sandstone which contains a very low concentration of the kaolinite (0.7\%). Figure 5 shows the pressure drop profile across the Bandera Brown (BB5) core on water injection. The change in pressure drop was very low compared to the change in pressure drop for Berea and Bandera Grey. The final permeability was $12.6 \mathrm{md}$ compared to the initial permeability of $14.9 \mathrm{md}$. This further support that kaolinite is responsible for fine migration on fresh water injection due to salinity contrast. Figure 6 shows the pressure drop profile across the Bandera Brown (BB6) on injection of $15 \mathrm{wt} \% \mathrm{HCl}$. The final to initial permeability ratio was 0.85 which was like the fresh water case. The damage caused by $15 \mathrm{wt} \% \mathrm{HCl}$ in sample BB6 can be attributed to illite that can migrate and plug the pore throat.

In summary, core flooding experiments suggest that the fresh water is more damaging to the formation which contains high kaolinite contents due to fine migration and salinity contrast. However, the damage by $\mathrm{HCl}$ was independent

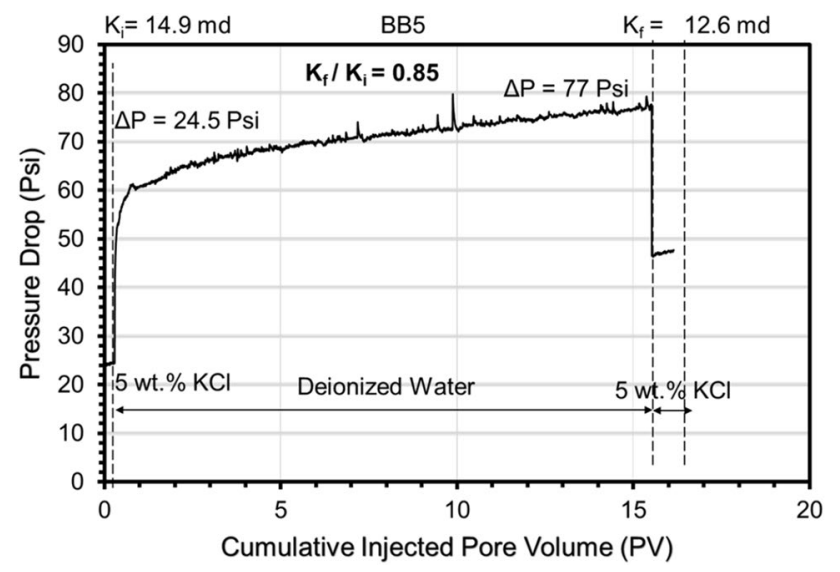

Fig. 5 Pressure drop across the sample Bandera Brown (BB5) as the deionized water injected at $5 \mathrm{~cm}^{3} / \mathrm{min}$ (backpressure $=1000 \mathrm{psi}$, confining pressure $=1700 \mathrm{psi}$ )

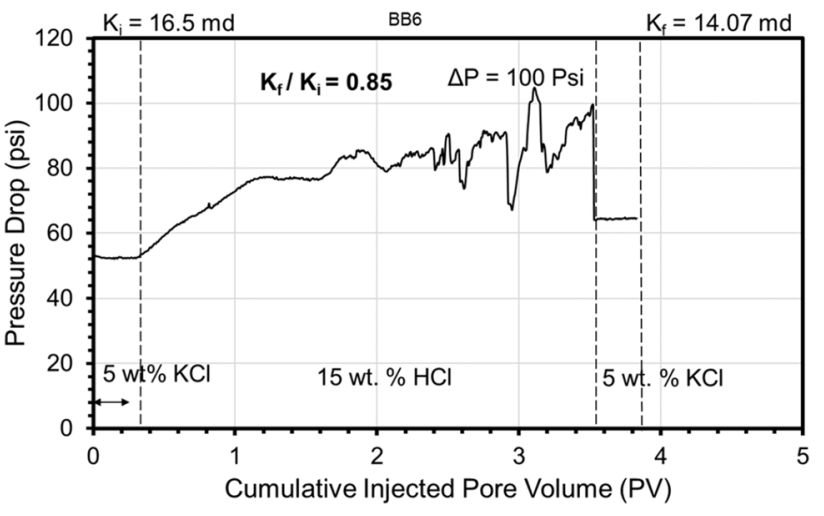

Fig. 6 Pressure drop across the sample Bandera Brown sandstone (BB6) as the $15 \mathrm{wt} \% \mathrm{HCl}$ injected at $5 \mathrm{~cm}^{3} / \mathrm{min}$ (backpressure $=1000 \mathrm{psi}$, confining pressure $=1700 \mathrm{psi}$ )

of kaolinite contents. For $\mathrm{HCl}$ injection, the damage depends on the competing reaction of $\mathrm{HCl}$ with different minerals.

The NMR experiments were conducted at three stages: after saturating the sample with $\mathrm{KCl}$ solution; after flooding the sample with damaging fluid (fresh water or $\mathrm{HCl}$ ); and after flooding the sample with $\mathrm{KCl}$ solution at the final stage. NMR results show the pore distribution of different core samples before and after flooding with damaging fluids. $\mathrm{T} 2$ signal distribution response showed that for all cores, the macropores represent the major contribution to the total porosity before flooding the damaging fluid. However, after flooding the damaging fluid, T2 signal distribution response was different for different cores and for different damaging fluid.

Figure 7a, b depicts the NMR T2 response curve for Bandera Grey core before and after damage at $25{ }^{\circ} \mathrm{C}$ for fresh water and $\mathrm{HCl}$ flooding. For fresh water flooding, incremental porosity and cumulative porosity are almost similar before and after flooding. This suggests that porosity of the Bandera Grey is not changing significantly with water injection. However, core flooding results showed that fresh water causes formation damage in Bandera Grey sandstone core. By compiling core flooding and NMR data, it was concluded that damage took place only in pore throats and pores remained unaffected. Bandera Grey contains $10 \%$ illite and $3 \%$ kaolinite. The damage was mainly due to fine migration (kaolinite) and clay swelling (illite). It also suggests that most of the clays were in mesopores that migrated to pore throats. For $\mathrm{HCl}$ flooding, there was a slight increase in the cumulative porosity. However, T2-relaxation curve shifted towards smaller relaxation time. The Bandera Grey core contains $16 \%$ dolomite that can react with the $\mathrm{HCl}$. The reaction could lead the dissolution of dolomite and result in the creation of more mesopores which is indicated by the shift of the incremental porosity curve towards smaller relaxation time. The core flooding data also suggest the damage to the core 
Fig. 7 a NMR T2 response curve for Bandera Grey core before and after damage at $25^{\circ} \mathrm{C}$ using water as a damaging fluid. b NMR T2 response curve for Bandera Grey core before and after damage at $25^{\circ} \mathrm{C}$ using $\mathrm{HCl}$ as a damaging fluid
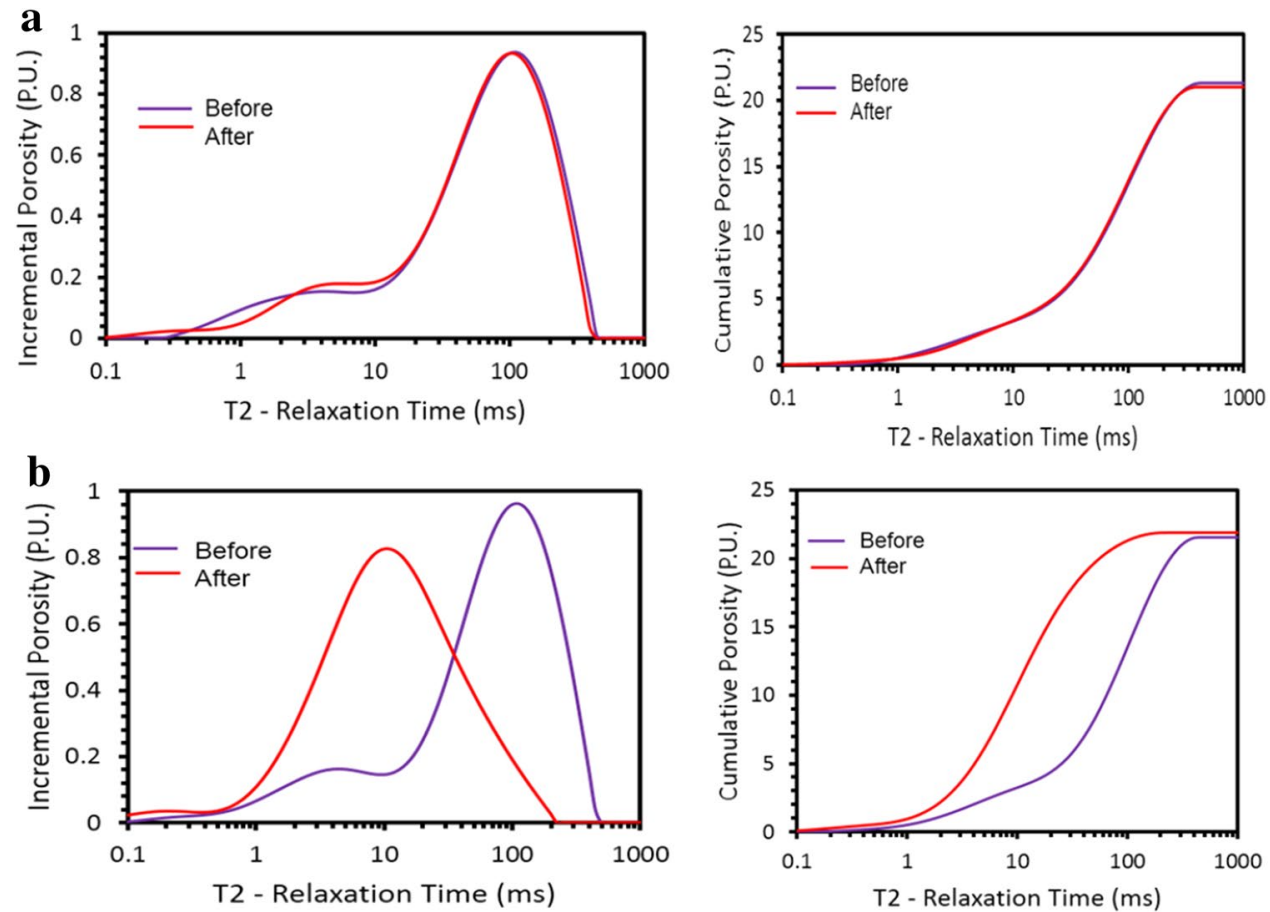

as final permeability reduced $\left(K_{\mathrm{f}} / K_{\mathrm{i}}=0.81\right)$. The damage is associated with the reaction of $\mathrm{HCl}$ to illite and chlorite. The dissolution can take place when $\mathrm{HCl}$ reacts with chlorite, however, it could also result in precipitation. Some of the precipitates can migrate towards the pore throat and reduce permeability.
Figure $8 \mathrm{a}, \mathrm{b}$ shows T2 distribution before and after flooding the samples BE3 and BE4 with deionized water and $15 \mathrm{wt} \% \mathrm{HCl}$, respectively. For fresh water, the measured porosity increased to $19 \%$ and in the pore character distribution, there is a small shift towards smaller relaxation time. No remarkable change observed within the small peaks
Fig. 8 a NMR T2 response curve for Berea sand stone core before and after damage at $25{ }^{\circ} \mathrm{C}$ using water as damaging fluid. b NMR T2 response curve for Berea sandstone core before and after damage at $25^{\circ} \mathrm{C}$ using $\mathrm{HCl}$ as damaging fluid
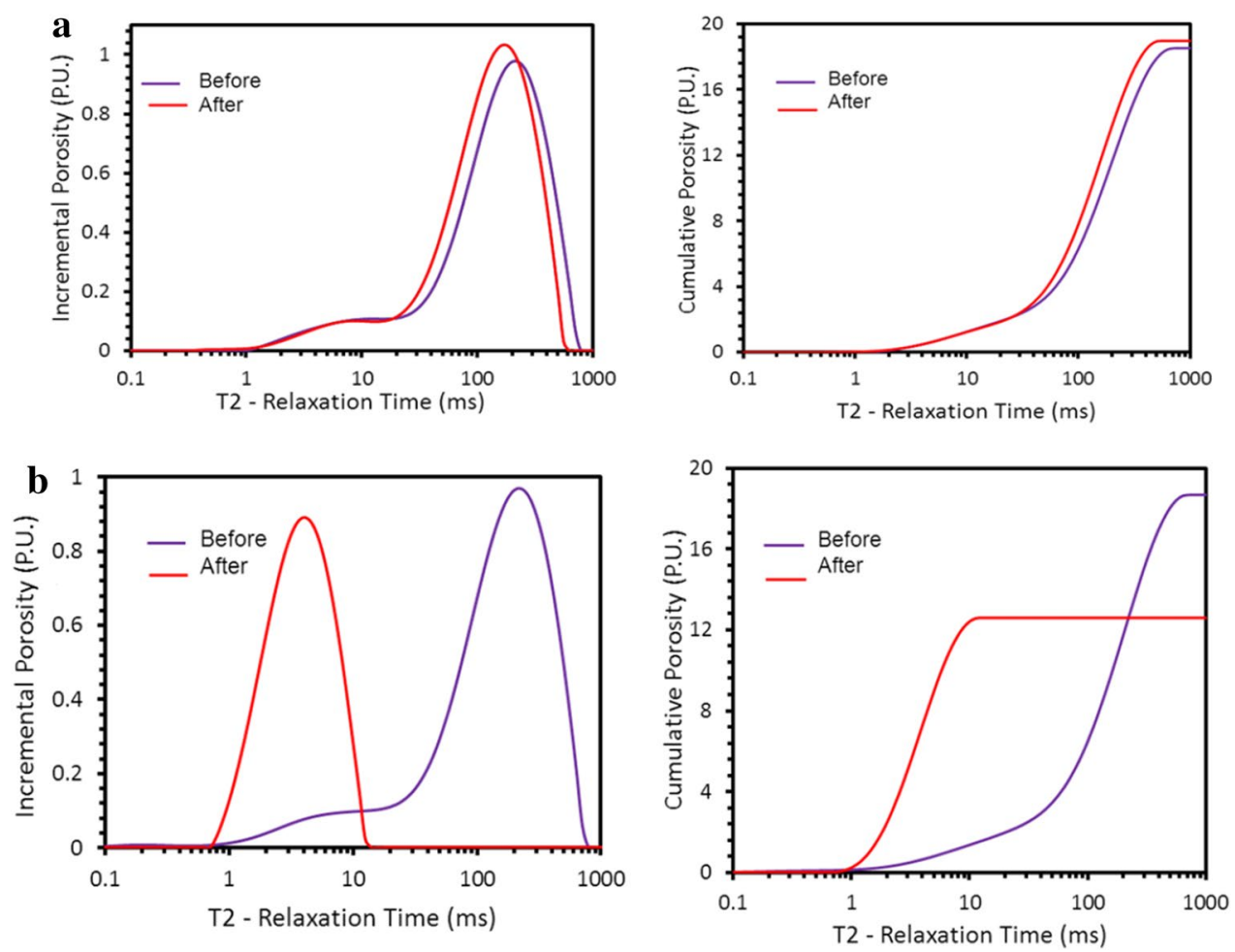
that correspond to the micropores. The core flooding data showed that there was a huge reduction in the permeability. This reduction in the permeability is associated with the fine migration of kaolinite which is 5\% in the Berea core. This fine migration plugs the pore throat and reduces the permeability. A minor increase in the porosity is also associated with fine migration from pores to pore throat. For $\mathrm{HCl}$, the system changed from bi-modal to uni-modal after the flooding. The long peaks shift toward small relaxation time which can be clearly noticed. The clays present in the rock can react with the $\mathrm{HCl}$ and cause dissolution and precipitation. For example, $\mathrm{HCl}$ can react with the dolomite (1\%) and calcite $(2 \%)$ present in the rock resulting in dissolution. The reaction of $\mathrm{HCl}$ with chlorite (2\%) could produce precipitate and reaction with illite can result in fine migration. There are competing mechanisms as dissolution is improving the permeability, while precipitation and fine migration are resulting in permeability reduction. The macropores were converted to mesopores because $\mathrm{HCl}$ reacted with illite and reduced the size of macropores to mesopores. In the same time, $\mathrm{HCl}$ reacted with calcite, dolomite, and chlorite in the rock and created more mesopores. The reduction in the porosity suggests that precipitate deposits in the pore.

T2-distribution response of Bandera Brown sandstone on water and $\mathrm{HCl}$ injection is shown Fig. 9a, b. Injection of fresh water can cause swelling of illite and fine migration of kaolinite. However, the incremental porosity and cumulative porosity was not changed much on injection of fresh water. Kaolinite was in minor fraction $(0.7 \%)$ in the Bandera brown, and therefore, fine migration was not severe. The illite was highest in the Bandera Brown core (5.2\%) compared to Berea and Bandera Grey. However, the formation damage in Bandera Brown $\left(K_{\mathrm{f}} / K_{\mathrm{i}}=0.85\right)$ was much less compared to Berea $\left(K_{\mathrm{f}} / K_{\mathrm{i}}=0.16\right)$ and Bandera Grey $\left(K_{\mathrm{f}} / K_{\mathrm{i}}=0.34\right)$. In the presence of dispersed clay, the formation damage should be more in Bandera Brown owing to the high concentration of illite. The lowest damage to Bandera Brown suggests that the illite was partially dispersed and the rest was structural clay. Injection of $\mathrm{HCl}$ caused a similar damage to the permeability that was observed for fresh water $\left(K_{\mathrm{f}} / K_{\mathrm{i}}=0.85\right)$. On injection of $\mathrm{HCl}$, the cumulative porosity increased while incremental porosity shifts towards smaller relaxation time. This shifting is an indication of the creation of micropores by the reaction of $\mathrm{HCl}$ with chlorite. As discussed previously, the reaction of $\mathrm{HCl}$ with chlorite can result in dissolution or precipitation. For precipitation, the $\mathrm{pH}$ should be approached to 2 . However, in this case, we used $15 \% \mathrm{HCl}$ and the $\mathrm{pH}$ was less than 1 . Therefore, the only dissolution occurs without any precipitation. The reaction of $\mathrm{HCl}$ with illite can cause fine migration that can settle in macropores. Therefore, the T2-relaxation response shifted towards smaller relaxation time.

The SEM images showed the morphology of the sandstone core samples before and after the damage. In addition,
Fig. 9 a NMR T2 response curve for Bandera Brown sandstone core before and after damage at $25^{\circ} \mathrm{C}$ using water as a damaging fluid. $\mathbf{b} \mathrm{NMR}$ $\mathrm{T} 2$ response curve for Bandera Brown sandstone core before and after damage at $25^{\circ} \mathrm{C}$ using $\mathrm{HCl}$ as a damaging fluid
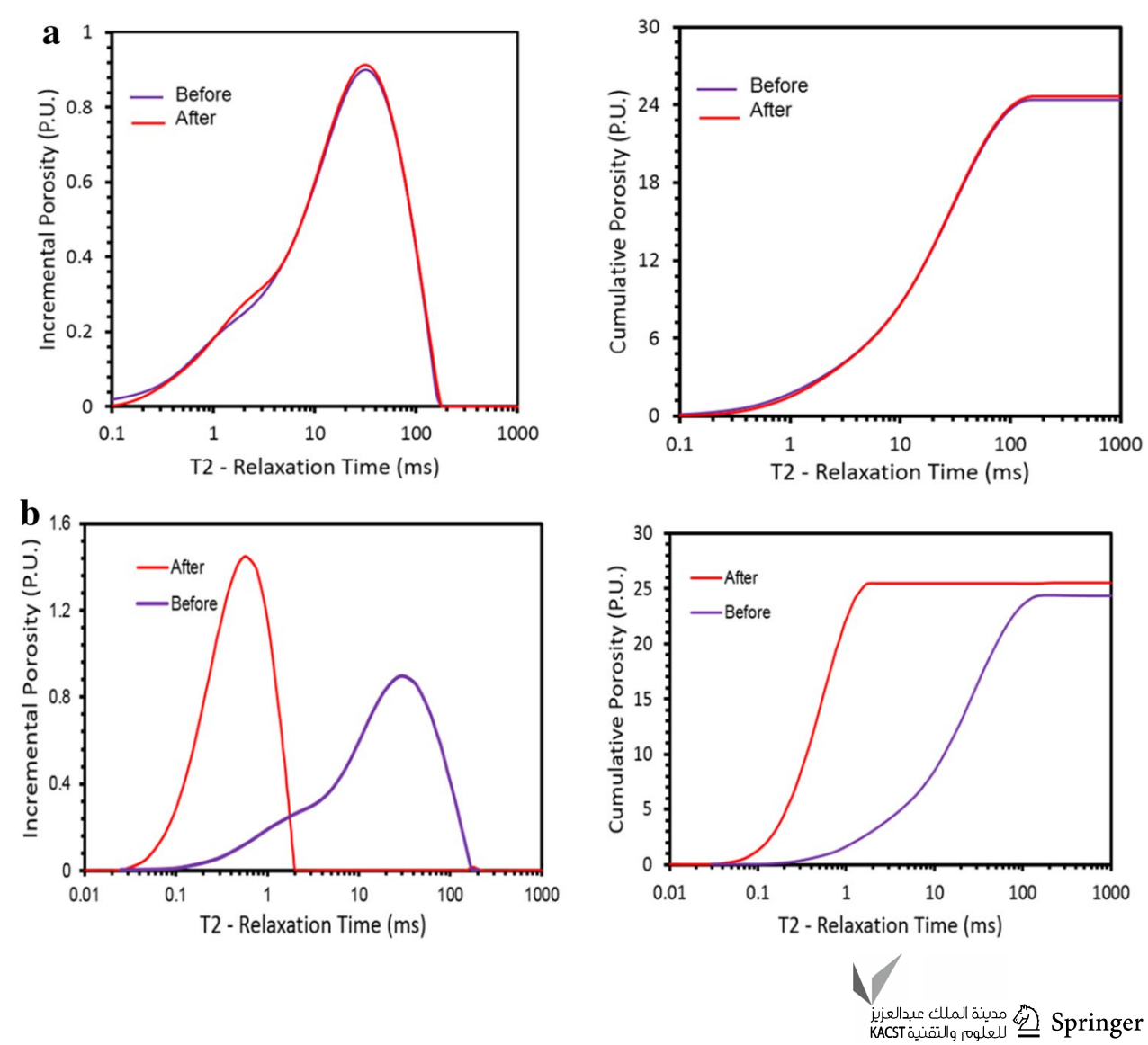
the images showed the clay minerals present in the sandstone rock. Figure 10 shows the SEM analysis of Bandera grey sandstone core plugs before and after injection of damaging fluid. SEM analysis shows that the formation damage took place by injecting fresh water that results in reduction of the permeability. After the core was injected with fresh water, the clays detached from the rock surface, migrate, and block the pore throat mainly. Some of the clays partially block the macropores. Figure 11 shows the morphology of Berea samples (BE3 and BE4) before and after flooding with damaging fluid (water for $\mathrm{BE} 3$ and $\mathrm{HCl}$ for $\mathrm{BE} 4$ ). The images shows a high amount of kaolinite with a small amount of chlorite and Illite before flooding. After the core was injected with fresh water, the clays detached from the rock surface, migrate and block the pore throat mainly (b). Some of the clays partially block the macropores. The $\mathrm{HCl}$ affect mainly the macropores in the case of the Berea sandstone (d). The clay migrated and mainly deposit at the surface of the macropores with less deposit at the pore throat.
Table 2 shows the summary of the rock properties for different sandstone rocks used in this study before and after treatment by $\mathrm{HCl}$ and fresh water. The initial permeability $\left(K_{\mathrm{i}}\right)$ and final permeability $\left(K_{\mathrm{f}}\right)$ cross plot in Fig. 12 shows that only two cores were severely affected by the damage. These two cores are Bandera Grey and Berea sandstone treated with fresh water. Other cores were not affected too much with the damaging fluids. There was no much difference between the initial porosity $\left(\phi_{\mathrm{i}}\right)$ and final porosity $\left(\phi_{\mathrm{f}}\right)$ except for Berea sandstone treated with $15 \mathrm{wt} \% \mathrm{HCl}$. Figure 13 shows the rock typing factor (RT) before and after damage. Similar conclusion was obtained from Fig. 13, only two cases have major change in the rock-typing factor. The two cores that have noticeable change in the rock-typing factors are Bandera Grey and Berea sandstone treated with fresh water. The rock-typing factor is the square root of permeability over porosity $=(K / \phi)^{0.5}$.
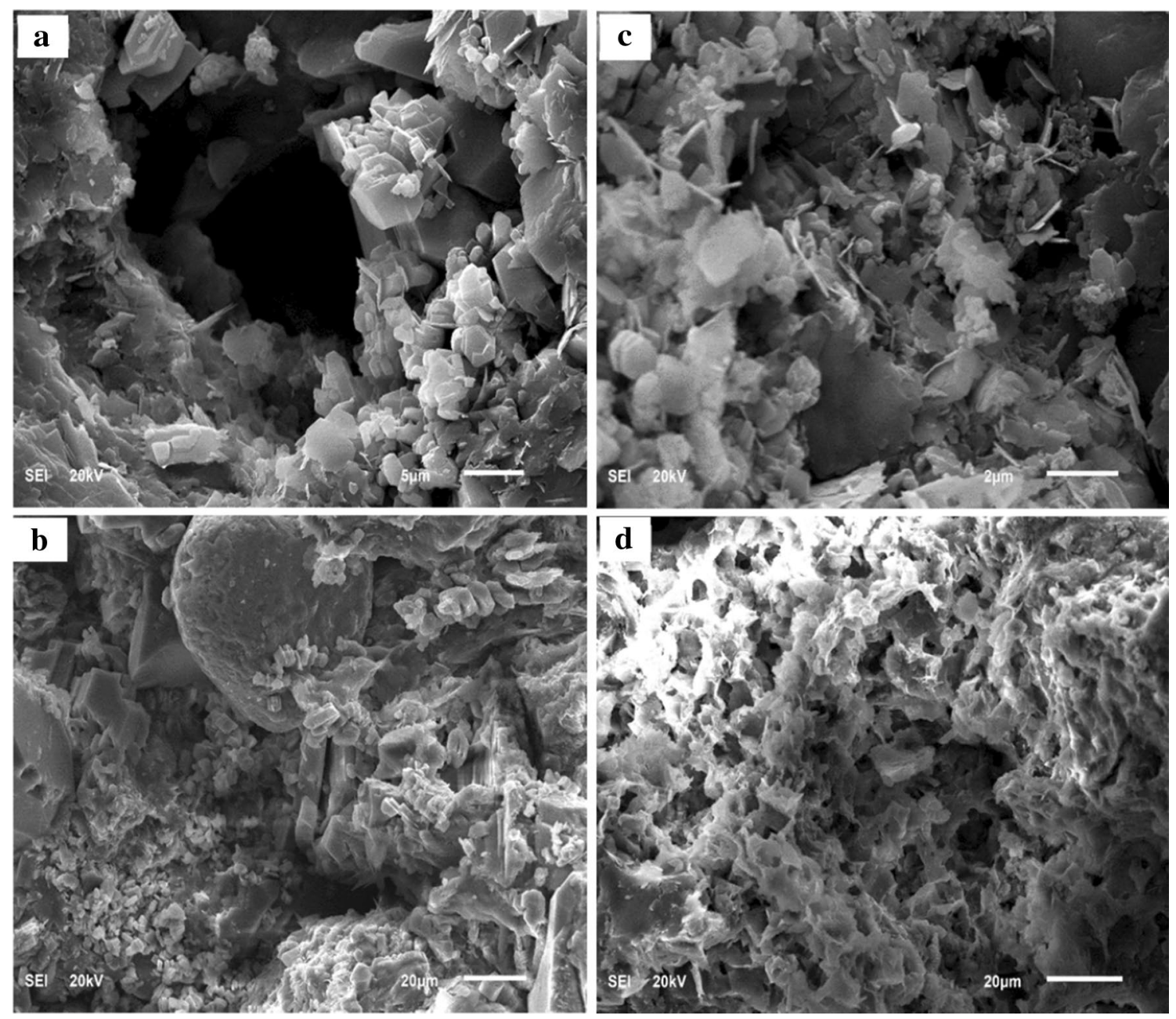

Fig. 10 SEM of Bandera Grey sandstone cores a BR1 before water flooding, b BR1 after water flooding, $\mathbf{c}$ BR2 before HCl flooding and d BR2 after $\mathrm{HCl}$ flooding

$\checkmark$

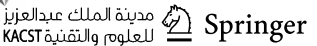



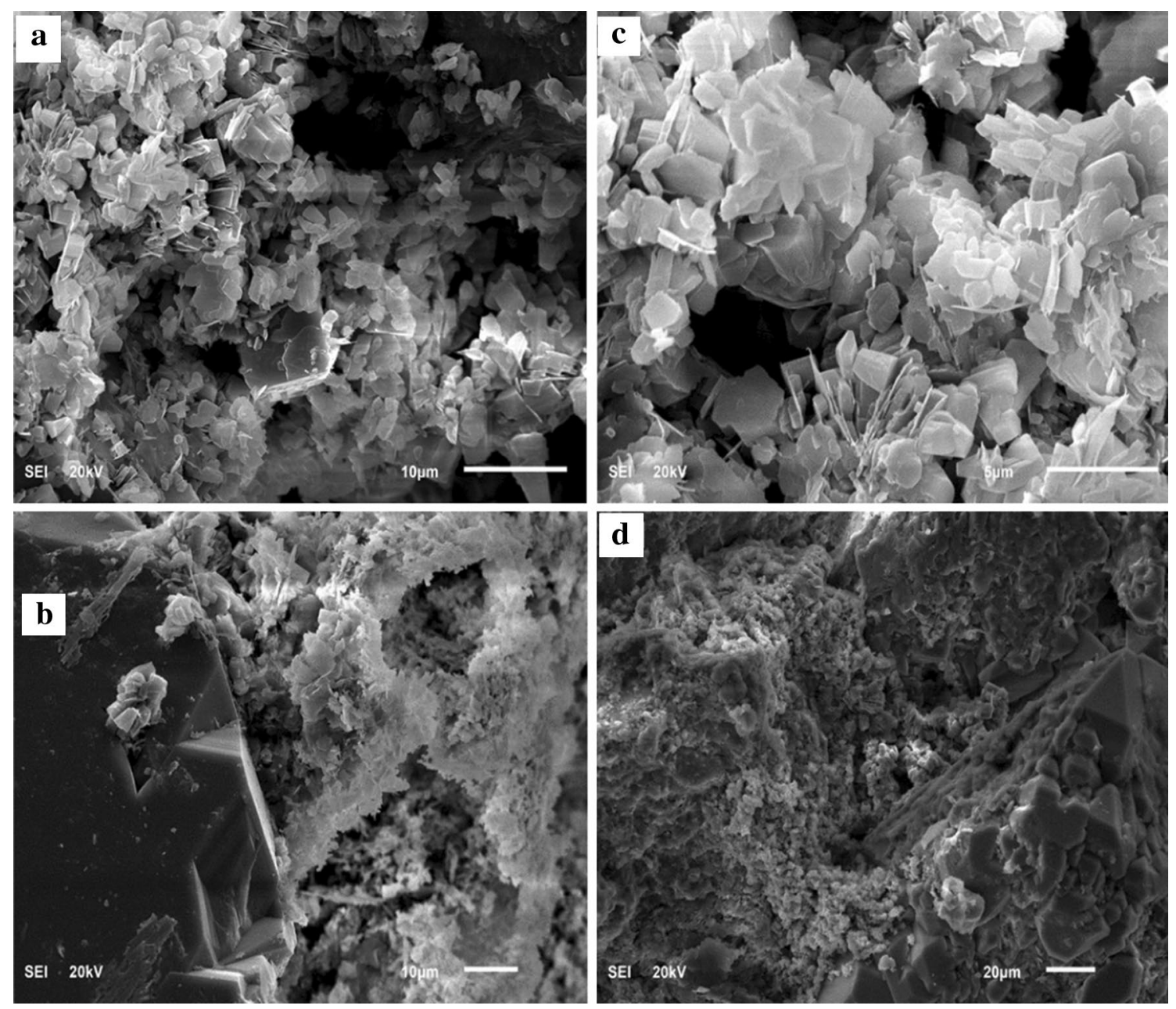

Fig. 11 SEM of Berea sandstone cores a BE3 before water flooding, b BE3 after water flooding, $\mathbf{c}$ BE4 before $\mathrm{HCl}$ flooding and $\mathbf{d}$ BE4 after $\mathrm{HCl}$ flooding

Table 2 Rock properties before and after damage

\begin{tabular}{llllllrr}
\hline Rock & Fluid & $K_{\mathrm{i}}(\mathrm{md})$ & $\phi_{\mathrm{i}}(\%)$ & $K_{\mathrm{f}}(\mathrm{md})$ & $\phi_{\mathrm{f}}(\%)$ & $R T_{\mathrm{b}}$ & $R T_{\mathrm{a}}$ \\
\hline Bandera Grey & Fresh Water & 48.5 & 21 & 16.6 & 20.7 & 15.2 & 9.0 \\
& $15 \mathrm{wt} \% \mathrm{HCl}$ & 27 & 20.8 & 22 & 21.2 & 11.4 & 10.2 \\
\multirow{3}{*}{ Berea Sandstone } & Fresh Water & 97.2 & 18 & 15.6 & 18.8 & 23.2 & 9.1 \\
& $15 \mathrm{wt} \% \mathrm{HCl}$ & 101.6 & 18 & 93.5 & 13 & 23.8 & 26.8 \\
Bandera Brown & Fresh Water & 14.9 & 23.8 & 12.6 & 24 & 7.9 & 7.2 \\
& $15 \mathrm{wt} \% \mathrm{HCl}$ & 16.5 & 23.5 & 14.07 & 25 & 8.4 & 7.5 \\
\hline
\end{tabular}

\section{Conclusion}

Impact of clay mineral contents on the formation damage of sandstone rock on injection of water or $\mathrm{HCl}$ was assessed using core flooding, NMR, and SEM analysis. The experiments were conducted using three different types of sandstone rocks (Bandera grey, Berea, and Bandera brown) that contain different clay mineral contents.
It was found that clay mineral types and contents have a major impact on the formation damage when water or $\mathrm{HCl}$ was injected with damaging fluids. The change in the pore system depends mainly on the clay mineral presence in the sample and the way it will react with the injected fluid. The permeability measurement showed the reduction in permeability after the damage induced. The reduction in permeability varied by the variation of the sample and the injected fluid. 
Fig. 12 Cross plot of initial versus final permeability

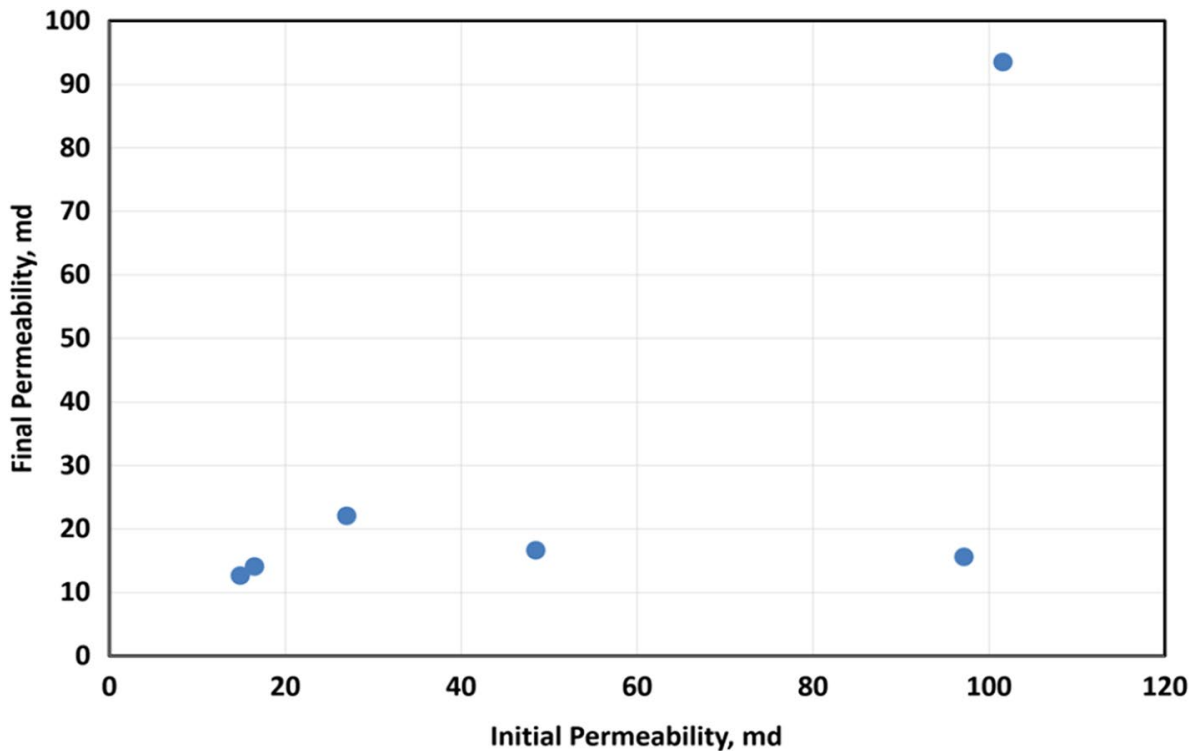

The maximum damage was observed for Berea sandstone core when water was injected as a damaging fluid. This reduction in the permeability $\left(K_{\mathrm{f}} / K_{\mathrm{i}}=0.16\right)$ was associated with the fine migration of kaolinite to the pore throat. The fresh water also causes damage to Bandera Grey sandstone core $\left(K_{\mathrm{f}} / K_{\mathrm{i}}=0.34\right)$ due to swelling of illite and fine migration of kaolinite. The damage due to fresh water was comparatively less in Bandera Brown $\left(K_{\mathrm{f}} / K_{\mathrm{i}}=0.85\right)$ as it contains a minor fraction of kaolinite $(0.7 \%)$. Although the illite in the Bandera Brown was 5.2\%, it was in structural form. The freshwater has little effect on the incremental and cumulative porosity that was obtained from the NMR. This suggests that fine migration affects the pore throat only.

The $\mathrm{HCl}$ was less damaging for Bandera Grey and Berea sandstone cores compared to the fresh water. However, for Bandera brown, the permeability reduction by $\mathrm{HCl}$ injection was like the permeability reduction by water. $\mathrm{HCl}$ can react

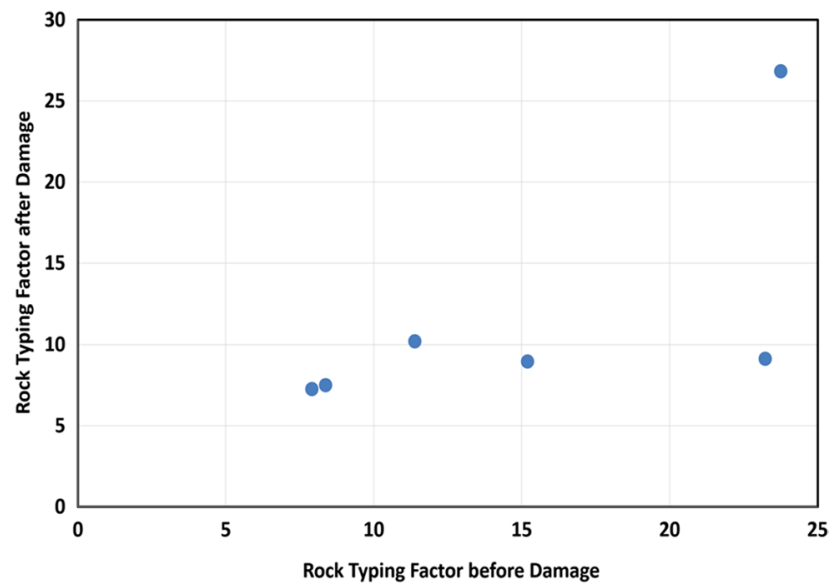

Fig. 13 Cross plot of rock-typing factor before and after damage with different clay minerals and either dissolution or precipitation can take place. The damage and porosity depend on the competing mechanism. For all core samples, $\mathrm{HCl}$ changes the porosity from macro to meso or micro.

Rock-typing factor and permeability cross plots before and after damage are good tools to assess the severity of damage in different sandstone rocks treated with different fluids.

Acknowledgements The authors would like to thank College of Petroleum Engineering \& Geosciences, King Fahd University of Petroleum \& Minerals, Saudi Arabia for providing the research support.

Open Access This article is distributed under the terms of the Creative Commons Attribution 4.0 International License (http://creativeco mmons.org/licenses/by/4.0/), which permits unrestricted use, distribution, and reproduction in any medium, provided you give appropriate credit to the original author(s) and the source, provide a link to the Creative Commons license, and indicate if changes were made.

\section{References}

Al-Yaseri AZ, Lebedev M, Vogt SJ, Johns ML, Barifcani A, Iglauer S (2015) Pore-scale analysis of formation damage in Bentheimer sandstone with in-situ NMR and micro-computed tomography experiments. J Petrol Sci Eng 129:48-57

Audibert A, Argillier J-F, Ladva HK, Way PW, Hove AO (1999) Role of polymers on formation damage. In: SPE European Formation Damage Conference, 1999. Society of Petroleum Engineers

Clarke T (2014) Application of a novel clay stabilizer to mitigate formation damage due to clay swelling. MSc Thesis, Texas A\&M University

Curbelo FD, Santanna VC, Neto ELB, Dutra TV Jr, Dantas TNC, Neto AAD, Garnica AI (2007) Adsorption of nonionic surfactants in sandstones. Colloid Surface A 293:1-4 
Ghofrani R, Mazeel A, Sengupta P (1992) Damage caused by claybased and clay-free inhibitive fluids in sandstone formations. In: SPE Formation Damage Control Symposium, 1992. Society of Petroleum Engineers

Hayatdavoudi A, Ghalambor A (1996) Controlling formation damage caused by kaolinite clay minerals: Part I. In: SPE Formation Damage Control Symposium, 1996. Society of Petroleum Engineers

Krueger RF (1988) An overview of formation damage and well productivity in oilfield operations: An update. SPE California Regional Meeting, 1988. Society of Petroleum Engineers

Mahmoud MA, Nasr-El-Din HA, De Wolf CA (2015) High-temperature laboratory testing of illitic sandstone outcrop cores with $\mathrm{HCl}$-alternative fluids. SPE Prod Oper 30:43-51

Neasham JW (1977) The morphology of dispersed clay in sandstone reservoirs and its effect on sandstone shaliness, pore space and fluid flow properties. In: SPE Annual Fall Technical Conference and Exhibition, 1977. Society of Petroleum Engineers

Paria S, Khilar KC (2004) A review on experimental studies of surfactant adsorption at the hydrophilic solid-water interface. Adv Colloid Interface Sci 110:75-95

Patzkó Á, Dékány I (1993) Ion exchange and molecular adsorption of a cationic surfactant on clay minerals. Colloid Surf A 71:299-307

Priisholm S, Nielsen B, Haslund O (1987) Fines migration, blocking, and clay swelling of potential geothermal sandstone reservoirs, Denmark. SPE Form Eval 2:168-178
ShamsiJazeyi H, Verduzco R, Hirasaki GJ (2014) Reducing adsorption of anionic surfactant for enhanced oil recovery: part I. Compet Adsorpt Mechan Colloid Surf A 453:162-167

Simon D, Anderson M (1990) Stability of clay minerals in acid. In: SPE Formation Damage Control Symposium, 1990. Society of Petroleum Engineers

Wilson L, Wilson M, Green J, Patey I (2014) The influence of clay mineralogy on formation damage in North Sea reservoir sandstones: a review with illustrative examples. Earth Sci Rev 134:70-80

Yu M, Mahmoud MA, Nasr-El-Din HA (2011) Propagation and retention of viscoelastic surfactants following matrix-acidizing treatments in carbonate cores. SPE J 16:993-991,001

Zhou Z, Gunter W, Jonasson R (1995) Controlling formation damage using clay stabilizers: a review. In: Annual Technical Meeting, 1995. Petroleum Society of Canada

Publisher's Note Springer Nature remains neutral with regard tojurisdictional claims in published maps and institutional affiliations. 